\title{
A new sarkomycin analog from Streptomyces sp. HS-HY-144
}

\author{
Li-fei Liu ${ }^{1,2}$, Huan $\mathrm{Qi}^{2}$, Hui Zhang ${ }^{2}$, Ji-dong Wang ${ }^{2}$ and Nie-fang Yu ${ }^{1}$ \\ The Journal of Antibiotics (2015) 68, 760-762; doi:10.1038/ja.2015.66; published online 10 June 2015
}

Sarkomycin is an antitumor antibiotic isolated from the culture filtrate of Streptomyces erythrochromogenes. ${ }^{1-3}$ Until 1960s, sarkomycin was used as a prescription drug to treat cancer in Japan. Although sarkomycin exhibits strong inhibitory effect on several cancer cell lines, the activity is not effective enough. ${ }^{3-5}$ A great effort has been extended to isolate or synthesize the analogous compounds of sarkomycin (Figure 1) expecting for more intensive antitumor chemicals with lower toxicity. ${ }^{6-10}$ During the course of searching for novel microorganism-derived antitumor secondary metabolites, we investigated the chemical constituents of a strain Streptomyces sp. HS-HY-144. As a result, a new sarkomycin analog (1, Figure 1) was isolated from the fermentation broth of the strain. In this paper, the details of isolation and structure characterization of compound 1 are described.

Strain Streptomyces sp. HS-HY-144 was isolated from a soil sample collected from a farmland located in Tengchong, Yunnan province, China. The strain was identified as the genus Streptomyces because its 16S rDNA sequence (accession no: KR232515) exhibited a high sequence similarity of $100 \%$ with that of S. mirabilis strain 3662 (accession no: EF371431.1).

The strain Streptomyces sp. HS-HY-144 was maintained on the medium containing glucose (Sinopharm Chemical Reagent Co, Ltd, Shanghai, China) $10 \mathrm{~g}$, maltose (Sinopharm Chemical Reagent Co, Ltd) $3 \mathrm{~g}$, yeast extract (Oxoid Ltd, Basingstoke, UK) $3 \mathrm{~g}$, $\mathrm{K}_{2} \mathrm{HPO}_{4} \cdot 3 \mathrm{H}_{2} \mathrm{O} 0.5 \mathrm{~g}, \mathrm{MgSO}_{4} \cdot 7 \mathrm{H}_{2} \mathrm{O} 0.5 \mathrm{~g}, \mathrm{NaCl} 0.5 \mathrm{~g}, \mathrm{KNO}_{3} 1 \mathrm{~g}$ and agar (Becton Dickinson and company, Franklin Lake, NJ, USA) $20 \mathrm{~g}$ in 1.01 of tap water, $\mathrm{pH}$ 7.0. The seed medium consisted of glucose $4 \mathrm{~g}$, maltodextrin (Shandong Xiwang Group Ltd, Binzhou, Shandong, China) $10 \mathrm{~g}$, yeast extract $4 \mathrm{~g}$ and $\mathrm{CaCO}_{3} 2 \mathrm{~g}$ in 1.01 water at pH 7.2-7.4. All the media were sterilized at $121^{\circ} \mathrm{C}$ for $20 \mathrm{~min}$. Slant culture was incubated for $6-7$ days at $28^{\circ} \mathrm{C}$. Fermentation was carried out in a 50-1 fermentor (containing 301 of production medium; Shanghai Guoqiang Bioengineering Equipment, Shanghai, China; THS-50 1), tank pressure control at $0.05 \mathrm{MPa}$. The producing medium was composed of glucose 1\%, soluble amylum (Haiyan Liuhe Starch
Chemical Co, Ltd, Haiyan, China) 4\%, yeast extract $0.5 \%$, soybean powder (Ningbo Beilun Jiangnan Grease Co, Ltd, Ningbo, China) $2.5 \%$, peptone (Sincere, Shanghai Sincere Biotech Co, Ltd, Shanghai, China) $0.5 \%, \mathrm{CaCO}_{3} 0.2 \%, \mathrm{MgSO}_{4} \cdot 7 \mathrm{H}_{2} \mathrm{O} 0.8 \%, \mathrm{FeSO}_{4} \cdot 7 \mathrm{H}_{2} \mathrm{O} 0.6 \%$, $\mathrm{ZnSO}_{4} \cdot 7 \mathrm{H}_{2} \mathrm{O} \quad 0.2 \%, \mathrm{MnSO}_{4} \cdot \mathrm{H}_{2} \mathrm{O} \quad 0.2 \%$ and $\mathrm{CoCl}_{2} \cdot 6 \mathrm{H}_{2} \mathrm{O} \quad 0.05 \%$, $\mathrm{Na}_{2} \mathrm{MoO}_{4} \cdot 2 \mathrm{H}_{2} \mathrm{O} 0.2 \%$ at $\mathrm{pH} 7.0$ before sterilization. The fermentation was conducted at $28^{\circ} \mathrm{C}$ for 7 days by stirring at $100 \mathrm{r} \mathrm{min}^{-1}$ with an aeration rate of 9001 of air per hour.

The final 301 of broth from the 50-1 fermentor was filtered, and the resulting cake was washed with water (31) and subsequently extracted with $\mathrm{MeOH}$ (31). The supernatant and the wash water were subjected to a Diaion HP-20 resin column eluting with 95\% EtOH (51). The $\mathrm{MeOH}$ extract and the $\mathrm{EtOH}$ eluents were evaporated under reduced pressure to 11 at $50{ }^{\circ} \mathrm{C}$, and the resulting concentrate was extracted three times using an equal volume of EtOAc. The combined EtOAc phase was concentrated under reduced pressure to yield a mixture $(23 \mathrm{~g})$. The mixture was chromatographed on a silica gel (Qingdao Haiyang Chemical Group, Qingdao, Shandong, China; 100-200 mesh) column and successively eluted with a stepwise gradient of $\mathrm{CHCl}_{3} / \mathrm{MeOH}(100: 0-50: 50, \mathrm{v} / \mathrm{v})$ to obtain three fractions Fr.1-Fr.3 based on the TLC profiles. TLC was performed on silica-gel plates $\left(\mathrm{HSGF}_{254}\right.$, Yantai Chemical Industry Research Institute, Yantai, China), with solvent system of $\mathrm{CHCl}_{3} / \mathrm{MeOH}$ (9:1). The developed TLC plates were observed under a UV lamp at $254 \mathrm{~nm}$ or by heating after spraying with sulfuric acid/ethanol, 5:95 (v/v). The Fr.2 was subjected to a Sephadex LH-20 gel (GE Healthcare, Glies, UK) column eluted with $\mathrm{CHCl}_{3} / \mathrm{MeOH}(1: 1, \mathrm{v} / \mathrm{v})$ and detected using TLC to give two fractions (Fr.2-1 to Fr.2-2). The Fr.2-1 was further isolated with semi-preparative HPLC (Agilent 1100, Zorbax SB-C18, $5 \mu \mathrm{M}$, $250 \times 9.4 \mathrm{~mm}$ inner diameter; $1.5 \mathrm{ml} \mathrm{min}^{-1} ; 220 \mathrm{~nm}$; Agilent, Palo Alto, CA, USA) eluting with $\mathrm{CH}_{3} \mathrm{CN} / 0.1 \%$ formic acid $(30: 70, \mathrm{v} / \mathrm{v})$ to give compound $1\left(t_{\mathrm{R}} 8.2 \mathrm{~min}, 83 \mathrm{mg}\right) .{ }^{1} \mathrm{H}$ and ${ }^{13} \mathrm{C}$ NMR spectra were measured with a Bruker DRX-400 $\left(400 \mathrm{MHz}\right.$ for ${ }^{1} \mathrm{H}$ and $100 \mathrm{MHz}$ for ${ }^{13} \mathrm{C}$ ) spectrometer (Bruker, Rheinstetten, Germany). The electrospray ionization mass spectrometry (ESIMS) and high resolution

${ }^{1}$ Institute of Drug Design and Discovery, Department of Pharmaceutical Chemistry, Central South University, Changsha, Hunan, China and ${ }^{2}$ Department of New Drug Screening, Zhejiang Hisun Pharmaceutical Co, Ltd, Taizhou, Zhejiang, China

Correspondence: Dr J-d Wang, Department of New Drug Screening, Zhejiang Hisun Pharmaceutical Co, Ltd, Taizhou Zhejiang 318000, China.

E-mail: jdwang@hisunpharm.com

or Professor N-f Yu, Institute of Drug Design and Discovery, Department of Pharmaceutical Chemistry, Central South University, Changsha, Hunan 410013, China. E-mail: niefang_yu@126.com

Received 30 March 2015; revised 8 May 2015; accepted 14 May 2015; published online 10 June 2015 

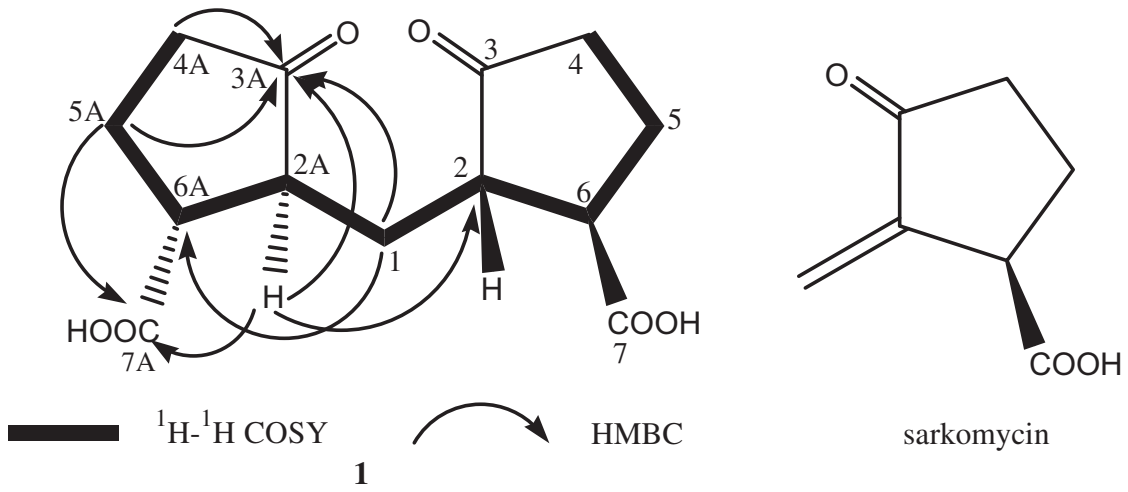

sarkomycin

Figure 1 Structures of 1 and sarkomycin, and the key ${ }^{1} \mathrm{H}-{ }^{1} \mathrm{H}$ COSY and $\mathrm{HMBC}$ correlations of 1.

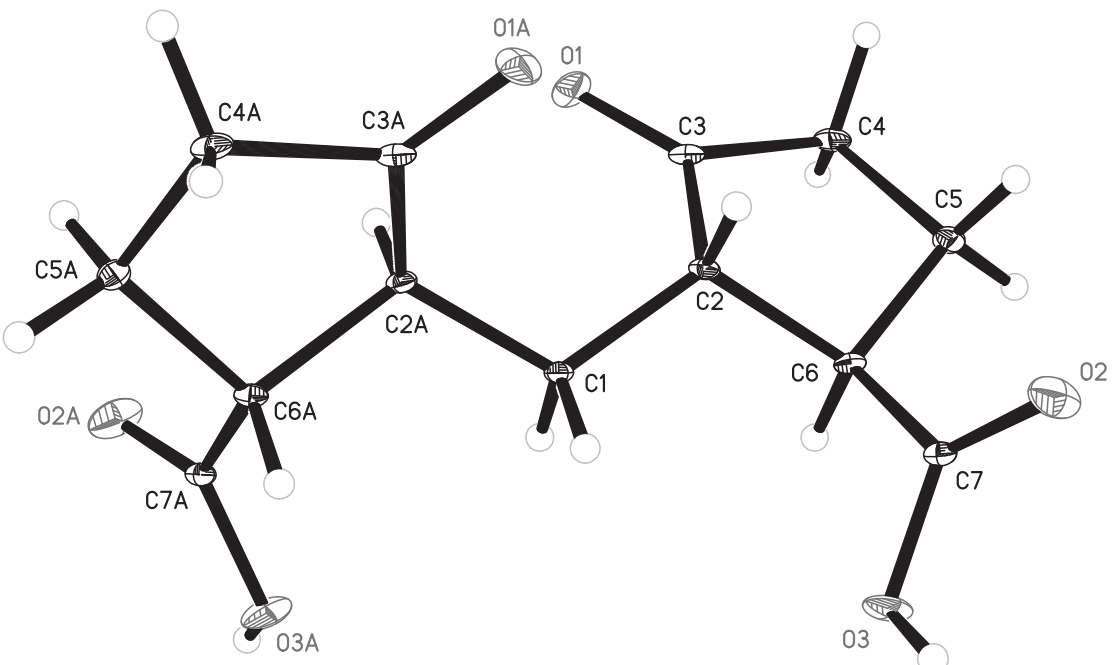

Figure 2 The X-ray crystallographic structure for 1 . A full color version of this figure is available at The Journal of Antibiotics journal online.

Table $1{ }^{1} \mathrm{H}$ and ${ }^{13} \mathrm{C}$ NMR data ${ }^{a}$ for compound 1

\begin{tabular}{lcc}
\hline Position & $\delta_{H}$ & $\delta_{C}$ \\
\hline 1 & $1.69 \mathrm{t}(6.8)$ & $27.7(\mathrm{t})$ \\
$2,2 \mathrm{~A}$ & $2.56 \mathrm{~m}$ & $48.6(\mathrm{~d})$ \\
$3,3 \mathrm{~A}$ & & $217.3(\mathrm{~s})$ \\
$4,4 \mathrm{~A}$ & $2.24 \mathrm{~m}$ & $36.3(\mathrm{t})$ \\
$5,5 \mathrm{~A}$ & $1.85 \mathrm{~m}$ & $24.2(\mathrm{t})$ \\
& $2.19 \mathrm{~m}$ & \\
$6,6 \mathrm{~A}$ & $2.77 \mathrm{~m}$ & $46.4(\mathrm{~d})$ \\
$7,7 \mathrm{~A}$ & 12.4 broad s & $175.3(\mathrm{~s})$ \\
$(\mathrm{COOH})$ & &
\end{tabular}

aChemical shifts are reported in parts per million ( $\delta$ ), using DMSO- $d_{6}\left(\delta_{\mathrm{H}} 2.50\right.$ p.p.m.; $\delta_{\mathrm{C}} 39.5$ p.p.m.) as an internal standard, with coupling constants $(J)$ in $\mathrm{Hz}$.

electrospray ionization mass spectroscopy (HRESIMS) spectra were taken on a Q-TOF Micro LC-MS-MS mass spectrometer (Waters Co, Milford, MA, USA).

Compound 1 was isolated as a colorless crystal (in $\mathrm{MeOH}$ ) with m.p. $237-239^{\circ} \mathrm{C},[\alpha]_{\mathrm{D}}^{25}+19.4(\mathrm{c} 0.2, \mathrm{EtOH})$ and $\mathrm{UV}(\mathrm{EtOH}) \lambda_{\max } \mathrm{nm}$ $(\log \varepsilon): 284$ (2.12). Its molecular formula $\mathrm{C}_{13} \mathrm{H}_{16} \mathrm{O}_{6}$ with $6{ }^{\circ} \mathrm{C}$ of unsaturation was determined using HRESIMS at $\mathrm{m} / \mathrm{z} 269.1015$ $[\mathrm{M}+\mathrm{H}]^{+}$(calculated as 269.1020 for $\mathrm{C}_{13} \mathrm{H}_{17} \mathrm{O}_{6}$ ). The IR spectrum displayed absorption band for carbonyl (at $1725 \mathrm{~cm}^{-1}$ ) functionality. Analysis of the ${ }^{1} \mathrm{H}$ and ${ }^{13} \mathrm{C}$ NMR data (Table 1 ) with the aid of DEPT experiment revealed the presence of three methylenes $\left(\delta_{\mathrm{C}} 24.2,27.7\right.$, $36.3)$, two aliphatic methines $\left(\delta_{\mathrm{C}} 46.4,48.6\right)$, one carboxyl carbonyl carbon $\left(\delta_{\mathrm{C}} 175.3\right)$ and one carbonyl group $\left(\delta_{\mathrm{C}} 217.3\right)$. The ${ }^{1} \mathrm{H}-{ }^{1} \mathrm{H}$ COSY correlations of $\mathrm{H}-2 \mathrm{~A} / \mathrm{H}-6 \mathrm{~A} / \mathrm{H}-5 \mathrm{~A} / \mathrm{H}-4 \mathrm{~A}$ (Figure 1) established the C-2A-C-4A structural fragment. The observed $\mathrm{HMBC}$ correlation networks of $\mathrm{H}-2 \mathrm{~A}, \mathrm{H}_{2}-5 \mathrm{~A}$ and $\mathrm{H}_{2}-4 \mathrm{~A} / \mathrm{C}-3 \mathrm{~A} ; \mathrm{H}-2 \mathrm{~A}, \mathrm{H}-6 \mathrm{~A}$ and $\mathrm{H}_{2}-5 \mathrm{~A} /$ $\mathrm{C}-7 \mathrm{~A}$ revealed the presence of a 3-oxocyclopentanecarboxylic acid moiety. The methylene group at $\delta_{\mathrm{C}} 27.7$ was connected to C-2A by the ${ }^{1} \mathrm{H}-{ }^{1} \mathrm{H}$ COSY correlation of $\mathrm{H}_{2}-1$ and $\mathrm{H}-2 \mathrm{~A}$ and the $\mathrm{HMBC}$ correlations from $\mathrm{H}_{2}-1$ to $\mathrm{C}-3 \mathrm{~A}$ and $\mathrm{C}-6 \mathrm{~A}$. Taking the molecular formula and ${ }^{13} \mathrm{C}$ NMR of $\mathbf{1}$ into account, $\mathbf{1}$ was probably included two 3-oxocyclopentanecarboxylic acid substructures. The linkage of the two 3-oxocyclopentanecarboxylic acid moieties via C-1 was corroborated by the HMBC correlations between $\mathrm{H}-2 \mathrm{~A} / \mathrm{C}-2$ and $\mathrm{H}-2 / \mathrm{C}-2 \mathrm{~A}$. To secure the assigned structure and also to determine its absolute configuration, a suitable crystal of 1 obtained from $\mathrm{MeOH}$ was subjected to X-ray diffraction analysis (Figure 2). The X-ray result not only completely agreed with the proposed structure but also 
allowed unambiguous assignment of its absolute configuration with absolute structure parameter $0.10(13)$ based on the final refinement on the $\mathrm{Cu} \mathrm{K \alpha}$ data. Thus, the structure of $\mathbf{1}$, including the absolute configuration, was confidently assigned.

Crystal data of compound 1 were collected using a Bruker APEX-II $\mathrm{CCD}$ with a graphite monochromated $\mathrm{Cu} \mathrm{K} \alpha$ radiation, $\lambda=1.54184 \AA$ at $140(2) \mathrm{K}$. Crystal data: $\mathrm{C}_{13} \mathrm{H}_{16} \mathrm{O}_{6}, \quad M=268.26$, monoclinic, space group $\mathrm{C} 2$; unit cell dimensions were determined to be $a=18.7920(4) \AA, b=5.82020(10) \AA, c=5.56990(10) \AA, \alpha=90^{\circ}$, $\beta=103.1570(10)^{\circ}, \quad \gamma=90^{\circ}, \quad V=593.21(2) \quad \AA^{3}, \quad Z=2, \quad D_{\mathrm{x}}=1.502$ $\mathrm{Mg} \mathrm{m}^{-3}, F(000)=284, \mu(\mathrm{Cu} \mathrm{K \alpha})=1.013 \mathrm{~mm}^{-1}$. Overall, 2485 reflections were collected until $\theta_{\max }=69.346^{\circ}$, in which independent unique 992 reflections were observed $[R($ int $)=0.0421]$. The structure was solved by direct methods using the SHELXS-2013 program (Sheldrick, 2013), and refined by the SHELXL-2013 program and full-matrix least-squares calculations. In the structure refinements, non-hydrogen atoms were placed on the geometrically ideal positions using the 'ride on' method. Hydrogen atoms bonded to oxygen were located by the structure factors with isotropic temperature factors. The final refinement gave $R=0.0434$, weighted residual factors $(\mathrm{RW})=$ 0.1119 , Flack $=0.10(13)$. Crystal data of 1 were deposited in the Cambridge Crystallographic Data Centre (CCDC 1054654).

The cytotoxicity of $\mathbf{1}$ was assayed for growth-inhibition activity in vitro against human cervical carcinoma HeLa cells using the sulforhodamine B (SRB) method. ${ }^{11}$ As a result, 1 showed poor cytotoxicity against the HeLa cells $(7.3 \%$ inhibition at the dose of $100 \mu \mathrm{M}$ ), whereas the $\mathrm{IC}_{50}$ value of the positive control (doxorubicin) was $0.234 \pm 0.015 \mu \mathrm{M}$.

The antimicrobial activity of $\mathbf{1}$ was assessed against the pathogenic bacterium Staphylococcus epidermidis with the broth microdilution MIC method recommended by the Clinical and Laboratory Standards Institute Standards ${ }^{12}$ using kanamycin monosulfate as a positive control. Compound 1 showed weak antibacterial activity (MICs: $1,10 \mathrm{mg} \mathrm{ml}^{-1}$; kanamycin monosulfate, $0.08 \mathrm{mg} \mathrm{ml}^{-1}$ ).
In previous report, sarkomycin exhibited strong cytotoxicity against HeLa cells. ${ }^{5}$ In this research, the bioassay showed that 1 exerted unfavorable cytotoxic activity on this cell line. This may be due to the reduction of the $\alpha, \beta$-unsaturated ketone moiety in 1 . This structural subunit existing in many natural products was demonstrated to be the key factor responsible for their antitumor activities and it was weak or inactive when the $\alpha, \beta$-unsaturated ketone moiety was absent. ${ }^{13}$ Studies on the biosynthetic pathway and other bioactivities of 1 are currently underway.

1 Umezawa, H., Takeuchi, T., Nitta, K., Yamamoto, T. \& Yamaoka, S. Sarkomycin, an anti-tumor substance produced by Streptomyces. J. Antibiot. 6, 101 (1953).

2 Umezawa, H. et al. Studies on anti-tumor substances produced by microorganisms. III. On sarkomycin produced by a strain resembling to Streptomyces erythrochromogenes. J. Antibiot. 6, 147-152 (1953).

3 Umezawa, H. et al. Sarkomycin, an anti-cancer substance produced by Streptomyces. Antibiot. Chemother. 4, 514-520 (1954).

4 Ishiyama, S., Hirayama, H., Takamura, M. \& Ohashi, T. Further observations upon the cytostatic effects of sarkomycin: an experimental study on the Ehrilich ascites carcinoma in mice. J. Antibiot. 7, 57-65 (1955).

5 Nitta, K. Studies on the effects of actinomycetes products on the culture of human carcinoma cells (strain HeLa). IV. Studies on sarkomycin and its derivatives. Jpn. J. Med. Sci. Biol. 10, 429-437 (1957).

6 Maeda, K. \& Kondo, S. Chemical studies on antibiotics of' Streptomyces. VI. Chemistry on sarkomycin. J. Antibiot. 11, 37-56 (1958).

7 Hara, T., Yamada, Y. \& Akita, E. Studies on sarkomycin. III. On the synthesis of 2-methylcyclopentanone-3-carboxylic acid and its activities. J. Antibiot. 10, 80-81 (1957).

8 Hara, T., Yamada, Y. \& Akita, E. Studies on sarkomycin. IV. Preparation of sarkomycin-INAH derivative and its stability. II. J. Antibiot. 10, 62-65 (1957).

9 Caputo, A., Brunori, M. \& Giuliano, R. Antitumoral action of new sarcomycin derivatives. I. Importance of ethyl radical and substituted methylene groups. Cancer Res. 21 1499-1509 (1961).

10 Caputo, A., Giovabella, B. \& Giuliano, R. Antitumoral action of new sarcomycin derivatives. Nature 190, 819-821 (1961)

11 Skehan, P. et al. New colorimetric cytotoxicity assay for anticancer-drug screening. J. Natl. Cancer Inst. 82, 1107-1112 (1990).

12 Clinical and Laboratory Standards Institute. Performance Standards for Antimicrobiol Susceptibility Testing. Seventh Edition: Approved Standard M7-A7. CLSI, Wayne, PA, USA (2006).

13 Hsiung, L., Shang, H., Claude, P., Joseph, P. \& Geissman, T. Cytotoxicity of sesquiterpene lactones1. Cancer Res. 31, 1649-1654 (1971) 